\title{
Teknik Tekstil Ekonomisi: \\ Gaziantep Non-woven Kumaş Piyasası
}

Erhan AKARDENIZ 


\section{(C) Copyright 2021}

Bu kitabın, basım, yayın ve satış hakları Akademisyen Kitabevi A.Ş.'ye aittir. Anılan kuruluşun izni alınmadan kitabın tümü ya da bölümleri mekanik, elektronik, fotokopi, manyetik kağıt ve/veya başka yöntemlerle çoğaltılamaz, basılamaz, dağıtılamaz. Tablo, şekil ve grafikler izin alınmadan, ticari amaçh kullanılamaz. Bu kitap T.C. Kültür Bakanlı̆̆ bandrolü ile satılmaktadır.

Bu kitapta yer alan fikirler ve düşünceler yazara ait olup, hiçbir kurum veya kuruluşun görüşünü yansıtmamaktadır. Bu kitap paylaşılan “Teknik Tekstil Endüstrileri: Nonwoven Kumaş Örneği ve Gaziantep’in Durumu” adlı yüksek lisans tezinden üretilmiştir.

\section{ISBN}

978-625-7496-91-9

\section{Kitap Adı}

Teknik Tekstil Ekonomisi: Gaziantep Non-woven Kumaş Piyasası

\section{Editör}

Prof. Dr. M. Hanifi ASLAN

ORCID iD: 0000-0002-6970-7480

Yazar

Erhan AKARDENIZ

ORCID iD: 0000-0003-2269-8182

\section{Yayın Koordinatörü Yasin DİLMEN}

\section{Sayfa ve Kapak Tasarımı}

Akademisyen Dizgi Ünitesi

\section{Yayıncı Sertifika No}

47518

\section{Baskı ve Cilt}

Vadi Matbaacilık

Bisac Code

BUS000000

\section{DOI}

10.37609/akya.721

\section{GENEL DAĞITIM}

\section{Akademisyen Kitabevi A.Ş.}

Halk Sokak 5 / A

Yenişehir / Ankara

Tel: o312 4311633

siparis@akademisyen.com 


\section{ÖNSÖZ}

Ülke kaynaklarının hangi üretim sahasında kullanılacağının seçimi ülke ekonomisi için son derece önem arz etmektedir. Ülkemizde uzun yıllardır tekstil alanında üretim artışı görülmektedir. Fakat bu alanda her sektörde olduğu gibi teknolojik ilerlemelerden ve yeniliklerden bağımsız hareket etmemektedir. Ülkeler yeni üretim teknikleri ve yeni kullanımları ile tekstili birçok noktaya taşımışlardır. Yapılan yenilikler beraberinde ticari bir perspektif ile ülkelerin ekonomisine yansıtılmaktadır. Her yenilik, patent ve isim hakkının alınmasını berberinde getirerek ülkesine çok yüksek katma değer olarak geri dönmektedir. Günümüzde uçaklardaki kompozit yapılardan yollardaki jeotekstillere kadar, spor malzemelerinden endüstride kullanılan malzemelere kadar birçok alanda bu yeni tekstilleri görmek mümkündür.

Genel itibariyle "bende yaparım" sloganıyla hareket etmektense "farklı ne yaparım" sorusuyla hareket etmemiz gerekmektedir. Konfeksiyon ve triko ve bunun yanında halı ve havlu gibi bilindik tekstil üretimleri demode olmuş yerini teknik tekstiller, akıllı tekstiller ve nano teknoloji gibi kavramları içeren üretim yöntemleri almıştır. Gaziantep açısından teknik tekstillere yapılan yatırımlar ülkemiz için çok önemli olmakla birlikte devamına ihtiyaç duyulmaktadır. Teknik tekstil alanında veya diğer katma değeri yüksek alanlarda üreticilerimizin uluslararası piyasalarda yarışabilmeleri için firmalarımızın maliyetleri, rakipleriyle aynı koşullara getirilmesi gerekmektedir. Bu sayede firmalarımız ve özellikle girişimcilik özelliği ön planda olan Gaziantep ilimizdeki üreticiler ülkeyi daha da ileriye taşımı̧̧ olacaklardır.

Bu çalı̧̧mada özellikle aileme ve çalı̧̧manın her aşamasında büyük emeği olan, engin bilgi ve tecrübesiyle bana yol gösteren danışman hocam sayın Prof. Dr. Mehmet Hanifi ASLAN' a sonsuz teşekkürlerimi sunarım.

Gaziantep, 2013 Erhan AKARDENIZZ 


\section{İÇINDEKILER}

Giriş .................................................................................................................

Teknik Tekstil Kavramı ve Sınıflandırma .......................................................5

2.1. Teknik Tekstilin Tanımı ve Özellikleri......................................................... 6

2.2. Teknik Tekstil Türleri ........................................................................... 10

2.2.1 Kullanım Alanlarına Göre .............................................................. 10

Giyim Tekstilleri (Clothtech) ............................................................ 11

Sportif Giysiler ve Tekstiller (Sportech) ............................................... 11

Koruyucu Giysiler (Protech) ................................................................. 13

Ev ve İç Mekân Tekstilleri (Hometech) ................................................ 13

Hijyen ve Tibbi Tekstilleri (Medtech) ................................................... 14

Endüstriyel Tekstiller (Indutecth) ...................................................... 14

İnşaat ve Yapı Tekstilleri (Builtech) ....................................................... 15

Jeotekstiller (Geotech) ...................................................................... 16

Tarım Tekstilleri (Agrotech) ............................................................... 17

Ekolojik Tekstiller (Oekotech) .............................................................. 18

Ulaşım Tekstilleri (Mobiltech)................................................................. 19

Ambalaj Endüstrisi Tekstilleri (Packtech)............................................. 20

2.2.2. Ürün Gruplarına Göre ......................................................................21

Dünya'da ve Türkiye’de Teknik Tekstil Endüstrisi ........................................25

3.1. Dünyada Teknik Tekstil Sektörünün Durumu, Önemi ve Geleceği ..................................................................................26

3.1.1. Teknik Tekstil Üretiminin Durumu ve Geleceğe Dair Üretim

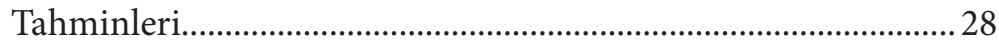

3.1.2 Tekstil Sektörünün Geleceğine Yön Verecek Ürünler.....................34

3.1.2.1. Teknik Tekstil Ürünleri ........................................................... 35

3.1.2.2. Akıllı Tekstil Ürünleri................................................................. 36

3.1.2.3. Dokunmamış (Non-woven) Tekstil Ürünleri........................ 38

3.1.3. Tekstil Üretimi Yerine Neden Teknik Tekstil Üretimi?................. 43

3.2 Dünyada Teknik Tekstil Endüstrilerinin Yapısı.......................................... 44

3.2.1. Genel Eğilimler ve Piyasa Büyüklüğ̈̈ ............................................... 45 
3.2.2. Teknik Tekstil Üretiminde Başlıca Ülkeler ................................. 58

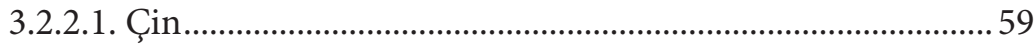

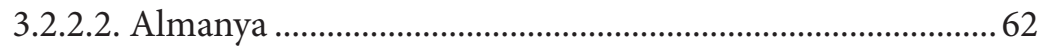

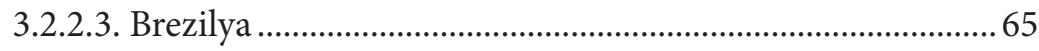

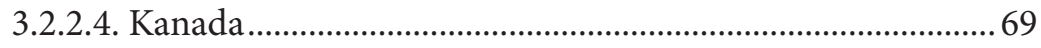

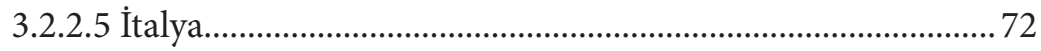

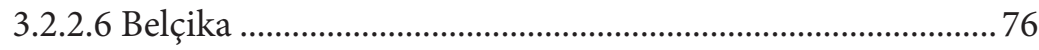

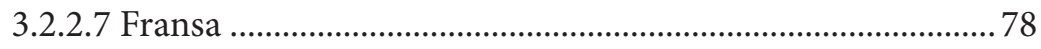

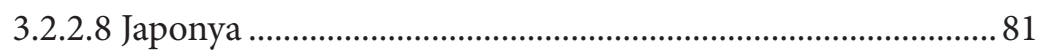

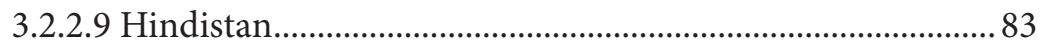

3.3. Türkiye’de Teknik Tekstil Sektörü ve Piyasa Yapısı...............................8 88

3.3.1. Genel Eğilimler ve Piyasa Büyüklüğü ......................................... 89

3.3.2. Teknik Tekstil Üretim Düzeyi .................................................... 90

3.3.3. Teknik Tekstil Dış Ticareti.......................................................... 91

3.3.3.1. Teknik Tekstillerin Yıllar İtibariyle Dış Ticareti................. 91

3.3.3.2. Temel Ürün Grupları İtibariyle Dış Ticaret.........................92 92

3.3.3.3. Ülkeler İtibariyle Diş Ticaret .............................................. 95

3.3.4. Türkiyede Teknik Tekstil Piyasasının Yapısı................................ 97

3.3.5. Türkiyede Teknik Tekstilin Geleceği .......................................... 99

4.1.1 Teknik Tekstil Üretimi ve Piyasa Yapısı ...................................... 103

Gaziantepte Teknik Tekstil Endüstrisi ve SWOT Analizi.......................103

4.1.2 Teknik Tekstil Tüketimi/Kullanımı ............................................. 108

4.1.3 Teknik Tekstil Dış Ticareti............................................................. 108

4.2. Gaziantep Non-woven Tekstil Firmaları ile Avrupa Firmalarının

Maliyet Karşılaştırması................................................................... 113

4.3. Gaziantep Non-woven Tekstil Endüstrisi İçin Swot Analizi............. 116

SWOT (Güçlü Yönler, Zayıf Yönler, Fırsatlar ve Tehditler) Analizi........ 116

Güçlü Yönler ve Zayıf Yönler ................................................................ 116

Güç̧ı̈ yönler .................................................................................... 116

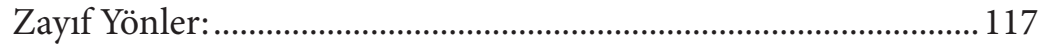

Firsatlar ve Tehditler .................................................................... 118

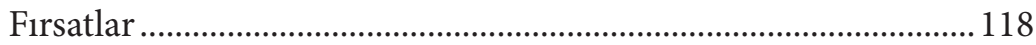

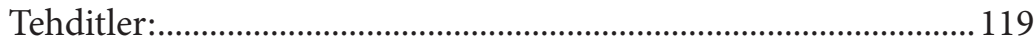

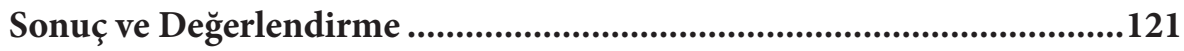




\section{KISALTMALAR}

$\begin{array}{ll}\text { ABD } & \text { Amerika Birlesik Devletleri } \\ \text { AB } & \text { Avrupa Birliği } \\ \text { AR-GE } & \text { Araştırma Geliştirme } \\ \text { ABIT } & \text { Assocoitei Brazil International Textilles } \\ \text { CBI } & \text { Karayip Havzası Girişimi } \\ \text { DİE } & \text { Devlet İstatistik Enstitüsü } \\ \text { INDA } & \text { Associaiton of the Nonwovens Fabrics Industry } \\ & \text { (Uluslararası Nonwoven Kumaş Endüstrisi Birliği) } \\ \text { İTKİB } & \text { İstanbul Tekstil ve Konfeksiyon İhracatç1ları Birlikleri } \\ \text { KOBİ } & \text { Küçük ve Orta Büyüklükte İsletme } \\ \text { NAFTA } & \text { Kuzey Amerika Serbest Ticaret Anlaşması } \\ \text { OECD } & \text { Ekonomik Kalkınma ve İşbirliği Örgütü } \\ \text { SWOT } & \text { Strenghts Weaknesses Opportunities Threats } \\ \text { TSE } & \text { Türk standartları Enstitüsü } \\ \text { ÜR-GE } & \text { Üretim Geliştirme } \\ \text { WTO } & \text { Dünya Ticaret Örgütü }\end{array}$




\section{KAYNAKLAR}

\section{Kitaplar}

Mortan, K. ve O.S.Arolat. (Şubat 2009) Gaziantep Ekonomisine Bakış. İstanbul:Heyemola Yayınları.

Akalın, M. ve İ. Mıstık. (2010) .Teknik Tekstiller. İstanbul: Birsen Yayınevi.

Yıldırım, M., Örnek, İ. (2010), Walt Whitman Rostow'un Kalkınma Aşamaları Yaklaşımına Göre Gaziantep Ekonomisinin İncelenmesi. A. Yiğidim (Ed.). Gaziantep Sanayinde İhracat, Finansman ve İstibdam Sorunları. Ankara: İmaj Yayınevi.

Kişoğlu, Erenler Çakar ve Bayraktar. (2005). Sayılarla Gaziantep-Kabramanmaraş Tekstil Sektörü Mevcut Durum-Beklentiler .Ankara:Türkiye Makine Mühendisleri Odası.

Luther, W.(2009). Nanomaterials. Hans, I. ve Bullinger J. (Ed.). Technology Guide. New York: Springer Publishing House .

Gowda, R.V.M.(2010). Advances in Yarn Spinning and Texturising. Alagirusamy, R. and Das,A. (Ed.) Technical Textiles Yarns. New York: Woodhead Publishing Limited .

Zhang, D.(2010). Nonwovens for Consumer and Industrial Wipes. Chapman, R.A. (Ed.) Applications of Nonworens in Technical Textiles. New York: Woodhead Publishing Limited .

Byrne, C.(2002).Teknik Tekstiller Piyasası. Horrocks, A. ve S. Anand (Ed.). Teknik Tekstiller El Kitabı. H. Kadoğlu (çev.). İstanbul:Türk Tekstil Vakfı.2003,1-23.

Slater, K.(2002).Teknik Tekstiller Piyasası. Horrocks, A. ve S. Anand (Ed.). Teknik Tekstiller El Kitabı. H. Kadoğlu (çev.). İstanbul:Türk Tekstil Vakfı.2003,529-543.

Örnek: Stodgill, M. R. ve A. E. Coons (Ed.). (1957). Leader Behaviour: Its Description and Measurement.

Saçak, M. (2002). Lif ve Elyaf Kimyası. Ankara: Gazi Kitabevi.

Ünsal, E.M.(2001). Mikro İktisat.4.Baskı.Ankara:İmaj Yayınevi.

Çoban, Y. (2012) Türkiye Ekonomisi. İstanbul: İkinci Sayfa Yayınları.

\section{Süreli Yayınlar}

Çokkeser, H.K. ve Çeven, E.K. (2011), Otomotivde Kullanılan Teknik Tekstiller. Kabramanmaraş Sütçü İmam Üniversitesi Mühendislik Bilimleri Dergisi. Cilt 14.Sayı 390, 48.

Tarakçıŏlu, I., D. Mecit, S. Ilgaz, D. Duran, G. Başal ve T. Gülümser, (2007), Teknik Tekstiller ve Kullanım Alanları. Tekstil ve Konfeksiyon Dergisi.17. 3, 154. http://www.tekstilvekonfeksiyon.com/en/technical-textiles-and-applications-part-2-2.html(28 Kasım 2012)

Kaynak, H.K., Değirmenci, Z.,(2010). Teknik Tekstil Uygulamalarında Kullanılan Nonwoven Filtreler. Tekstil Teknolojileri Elektronik Dergisi. 4. 2: 78-84 http://www.teknolojikarastirmalar.com/pdf/tr/04_2010_4_2_84_534.pdf(24 Nisan 2013)

Kopar, M. (2010), Chp Teştif Raporlarına Göre II.Dünya Savaşında Gaziantep. Gaziantep Üniversitesi Sosyal Bilimler Dergisi. 10. 3,1040.

Filiztekin, A. (2006). Türkiye'de Açıklanmış Karşılaştırmalı Üstünlüklerin Evrimi. The Evolution of Revealed Comparative Advantage in Turkey), Uluslararası Ekonomi ve Dış Ticaret Politikas1 (International Economies and Foreign Trade Policy), 1(1), 101-116.

Devlet Planlama Teşkilatı Müsteşarlı̆̆ı. (2006). Tekstil, Deri ve Giyim Sanayii Özel İhtisas Komisyonu Raporu. Dokuzuncu Kalkınma Planı 2007-2013. Şubat

Kaufmann, J. ve Kroszner, S. (2007). Opportunities Abound For Technical Textiles. Textile World. May/June 2007, 31-33.

Kamran, M.I. (2009). The Applications of Nonwovens in Technical Textiles. Technical Textiles \& Nonwovens. December 2010, 37.

Tekstil Dünyası Dergisi.(2013) Gaziantep Yatırım Teşviklerinin Gözdesi. 2. 62, 69-70.

Thread.(2006) Market for Technical Textiles in Brazil. http://www.nwtexnet.co.uk/images/ newsletters/Thread6.pdf,(15 Nisan 2013) 
Kilduff, P.(2001), Evolving Strategies, Structures and Relaitionship in Complex and Turbulant business Environments: The Textile and Apperel Industries of The New Millenium. North Carolina State University Journal of Textile And Apparel,Technology And Managmenti. 1.2:1. http://citeseerx.ist.psu.edu/viewdoc(23Şubat 2013)

Heymann, E.(2011) Innovation and Internationalisation as Success Factors. Speyer, B. (Ed). (2011). Textile and Clothing Industry. Frankfurt am Main Germany: Deutsche Bank Research

Kuru, A. ve Alay Aksoy, S. (2012). Faz Değiştiren Maddeler ve Tekstil Uygulamaları, Tekstil ve Mühendis. 19.86, 41-48.

Kayacan, O. ve Bulgun, E.Y. (2005). Akıllı Tekstiller ve Elektriği İleten Tekstil Esaslı Malzemeler, Tekstil ve Mühendis. 12.58, 30.

Cireli, A., Kutlu, B., Onar, N. ve Erkan, G.. (2006). Tekstilde İleri Teknolojiler, Tekstil ve Mühendis. 13.61,1.

Alüftekin, N., Yüksel, Ö., Taş, A., Çakar, G. ve Bayraktar, F. (2012). Küresel Krizden Çıkışta Kümelenme Modeli: Tekstil ve Hazır Giyim Sektörü Örneği. Uluslararası Yönetim İktisat ve İsletme Dergisi, 5.10, 1-19.

Güneşoğlu, C. (2009). Nanoteknoloji ve Tekstil Sektöründeki Uygulamaları, Mühendis ve $M a-$ kina Dergisi. 50. 591, 27-28.

Schmidt, O. (2012). Textiles and Textile Technology, Technical Textiles Trends and Opportunities. http://www.euratex.org/system/files/attached-files/14062012-A2Euratex_Public_GA_ Messe_Frankfurt_Presentation.pdf

Yalçınkaya, B. ve Yılmaz, D. (2011). Elektronik Tekstillerin Tekstil Endüstrisindeki Yeri ve Giyilebilir Tekstilde Kullanılan İletken Lifler. Tekstil Teknolojileri Elektronik Dergisi, 5.1, 63-64.

Chugan,P.K.(2011), Diversification into Technical Textiles: A Forward Momentum for Indian Textile Industry. Nirma University Journal of Business and Management Studies. 6.1:1-27. http://papers.ssrn.com/sol3/papers.cfm?abstract_id=1836283 (20 Nisan 2013)

\section{Diğer Yayınlar}

Kalebek, N.A. ve Babaarslan, O. (2005). Nonwoven Endüstrisi: Gelişen ve Genişleyen Sektör. Tekstil Teknolojileri ve Tekstil Makinalar Kongresi. Gaziantep: Tmmob, s.7.

Kayacan, O., Kayacan,Ö., Erdoğan,Ü.H., Erkan, G. (2005). Teknik Tekstiller Endüstrisi ve Eğitimi. Tekstil Teknolojileri ve Tekstil Makinaları Kongresi. Gaziantep: Tmmob, s.120-121.

Babaarslan, O. (2007). Bilim ve Teknoloji Perspektifinden Teknik Tekstil Nedir? Ne Değildir?, II. Tekstil Teknolojileri ve Tekstil Makinaları Kongresi. Gaziantep: Tmmob, s.137.

Smith, C.W. (2007). Teknik Tekstiller Endüstrisi Kuzey Amerika, Greer . http://www.intexa.com/downloads/techtextiles_talk.pdf(24 Nisan 2013)

Onar N, ve Sarışık M.(11-12 Ekim 2002). Tıbbi Tekstillerin Özellikleri ve Sınıflandırılması. Uluslararası Teknik Tekstiller Kongresi. İzmir: Dokuz Eylül Üniversitesi, 218.

Cireli, A., Kayacan, Ö. ve Erdoğan, Ü.H. (11-12 Ekim 2002). Teknik Tekstiller ve Kullanım Olanakları. Uluslararası Teknik Tekstiller Kongresi. İzmir: Dokuz Eylül Üniversitesi, 13-14.

Tekstil İsveren Dergisi. (2012), Gelecek Tekstilden İbaret Olacak. 6.390,8.

Mukhopadhyay, S. K. (2003). Introduction. Journal of the Textile Institute, 94(3-4), 1-2. http:// www.tandfonline.com/do(23 Şubat 2013)

Öngüt Ç.E. (2007). Türk Tekstil ve Hazır Giyim Sanayiinin Değişen Dünya Rekabet Şartlarına Uyumu. Uzmanlık Tezi. Ankara: Devlet Planlama Teşkilatı.

Balcı, H. (2006). Akıllı(fonksiyonel) Tekstiller, Seçilmiş Kumaşlarda Antibakteriyel Apre ve Performans Özellikleri. Yayınlanmamış Yüksek Lisans Tezi. Adana: Çukurova Üniversitesi Fen Bilimleri Enstitüsü

Advantage Austria. (2012). Exportbericht. Mart. Wien/Avusturya. 
Emek, A.(2004). Teknik Tekstiller Dünya Pazarı, Türkiye'nin Üretim ve İhraç İmkanları. Uzmanlık Tezi. Ankara:T.C. Başbakanlık Dış Ticareti Geliştirme Etüd Merkezi

Alsaç, F.(2010). Bölgesel Gelişme Aracı Olarak Kümelenme Yaklaşımı ve Türkiye için Kümelenme Destek Modeli Önerisi. Uzmanlık Tezi. Ankara: Devlet Planlama Teşkilatı.

Coşkun, E.(2007) Akıllı Tekstiller ve Genel Özellikleri. YayınlanmamışYüksek Lisans Tezi. Adana: Fen Bilimleri Enstitüsü

Çınar, E.(2007). Teknoliflerin Lif Sanatındaki Yeri. Yayınlanmamış Yüksek Lisans Tezi. İstanbul: T.C. Mimar Sinan Güzel Sanatlar Üniversitesi Sosyal Bilimler Enstitüsü

Görgülü, A. (2006). Türkiye'de Tekstil ve Hazır Giyim Sektöründe Markalaşma ve İhracata Etkileri, Yayınlanmamış Yüksek Lisans Tezi. Bursa: Uludağ Üniversitesi Sosyal Bilimler Enstitüsü

Gündoğdu, B.(2011). Türk Bankacılık Sektöründe Yoğunlaşma ve Rekabet. YayınlanmamışYüksek Lisans Tezi. Ankara: Ankara Üniversitesi Sosyal Bilimler Enstitüsü

Güney, S.(2009). Peristaltik Hareket Sağlayan Tıbbi Tekstil Metaryelinin Geliştirilmesi ve Bilgisayarlı Kontrolü. Yayınlanmamış Yüksek Lisans Tezi. Isparta: T.C. Süleyman Demirel Üniversitesi Fen Bilimleri Enstitüsü

Güleryüz, Ö.(2011). Küresel Gelişmeler Işığında Türkiye'de Tekstil Sektörü ve Geleceği. Tezsiz Yüksek Lisans Bitirme Projesi. Isparta: T.C. Süleyman Demirel Üniversitesi Sosyal Bilimleri Enstitüsü

Uçar, S. (2006). Teknik/Akıllı Tekstiller ve Tasarımda Kullanımları. Yayınlanmamış Yüksek Lisans Tezi. İstanbul:T.C. Mimar Sinan Güzel Sanatlar Üniversitesi Sosyal Bilimler Enstitüsü

Kayalı, B. (2010). Uluslar arası İşbölümü ve Gaziantep Tekstil Sektörü. Yayınlanmamış Yüksek Lisans Tezi. Ankara:T.C. Ankara Üniversitesi Sosyal Bilimler Enstitüsü

Gülsoy, E.(2010). Teknik Tekstiller. T.C. Başbakanlık Dış Ticaret Müsteşarlığ1 İhracatı Geliştirme Etüd Merkezi

Partner Grupa Syndex.(2011). Technical textiles Market Trends and Challenges Crisis, Restructuring and Major Companies Strategies. The European Trade Union Federation of Textiles Leather Clothing

Gültekin, S.(2011). Gaziantep Executive Summary Economic Sectoral Review E'Cluster Selection. Kobi İşbirliği ve Kümelenme Projesi. http://www.smenetworking.gov.tr/userfiles/pdf/ ekonomikanalizler/ExecutiveSummaryEconomicSectoralReviewGaziantepFinal.pdf $\quad$ (10 Haziran 2013)

TUIKK. (2013). Kişi Başına GSYİH. http://www.tuik.gov.tr/VeriBilgi.do?alt_id=55 (10 Mayıs 2013).

TUİK. (2011).Adrese Dayalı Nüfus Kayıt Sistemi. http://www.tuik.gov.tr/PreTablo.do?alt_id=39 (17 Kasım 2012).

TUIKK. (2008). Dış Ticaret İstatistikleri ve Endeksleri. http://www.tuik.gov.tr/PreTablo.do?alt_ id=13 (31 Aralik 2012).

Türkiye Cumhuriyeti Gümrük ve Ticaret Bakanlığı.(2011). Pamuk Raporu http://www.gumrukticaret.gov.tr/altsayfa/icerik/175/1311/2011-raporlari.html (22 Ağustos 2012)

Türkiye Sanayi ve Ticaret Bakanlığı.(2010). Türkiye Sanayi Stratejisi Belgesi http://www.sanayi. gov.tr/Files/Documents/sanayi_stratejisi_belgesi_2011_2014.pdf

(01 Mart 2013)

Türkiye Giyim Sanayicileri Derneği.(2010). Teknik Tekstiller ve Yenilikçilik http://www.tgsd. org.tr/phocadownload/2010bultenler/2010mart.pdf (02 Temmuz 2013)

Italy Trade Coommission (2011). China Technical Textile Industry Survey http://www.ice.gov.it/ paesi/asia/cina/upload/174/China_Technical_Textile_Industry_2011.pdf (24 Şubat 2013)

Australian Trade Coommission (2011). Technical Textiles to Germany http://www.austrade.gov. $\mathrm{au} /$ Technical-textiles-to-Germany(02 Mart 2013)

The Made in Italy Official Portal (2013) Technical Textiles:Italian Innivationhttp://www.italtrade.com//focus/6221.(16 Nisan 2013)

Pakistan Textile Journal (2013) Italian Review http://www.ptj.com.pk/Web-2009/08-09/ Growth.htm(16 Nisan 2013) 
Noor, F., Peters, S.,Stingelin-Stutzmann, N. ve Smith., P.(2008). Going Agaisnt the Grain: The Dematurity of the European Textile. Universty of London, School of Engineering and Materials Science. http://www.globelicsacademy.org/2008/2008_student_presentations/ Noor_GA08.pdf (16 Nisan 2013).

Türkiye Odalar ve Borsalar Birliği (2011). 67. Genel Kurul Ekonomik Rapor 2011.Ankara

Türkiye Bilimsel ve Teknolojik Araştırma Kurumu (2003). Vizyon 2023 Teknoloji Öngörüsü Projesi. Ankara

Türkiye Odalar ve Borsalar Birliği.(2012) Sanayi Veri Tabanı. http://sanayi.tobb.org.tr/kitap_ son2.php?kodu=139510 (14 Haziran 2013)

Ekonomi Bakanlığı İhracat Genel Müdürlüğü Tekstil ve Konfeksiyon Ürünleri Daire Başkanlığı. (2012). Teknik Tekstiller Sektörü.Ankara.

Ekonomi Bakanlığ Sao Paulo Ticaret Ataşeliği(2013). Brezilya’nın Tekstil ve Konfeksiyon Sektörü Hakkında Not.Ocak. http://www.musavirlikler.gov.tr/upload/BRZ/tekstil_konfeksiyon (24 Nisan 2013)

Türkiye Cumhuriyeti Ekonomi Bakanlığı İhracat Bilgi Bilgi Platformu(2007) Producer sor Exporters of Technical Textiles and Non-woven in Turkey http://www.ibp.gov.tr/ihrlist/Technical_firms.pdf ( 07 Mayıs 2013)

European Economic and Social Committee (2013). Growth Driver Technical Textiles. Mart. Brüksel. http://www.eesc.europa.eu/?i=portal.en.ccmi-opinions.24262(10 Mayıs 2013)

Ministry of Textiles Government of India. (2004). Report of the Expert Commite on Technical Textiles.http://smallb.in/sites/default/files/knowledge_base/reports/ReportontheexpertCommitteeonTechnicalTextilesVolumeI.pdf (03 Mart 2013)

Ministry of Textiles Government of India. (2011). Technology Mission on Technical Textiles. http://www.nitracoeprotech.org/pdf/textile-coe.pdf( 05 Ocak 2013)

Ministry of Textiles Government of India. (2010). Speciality Fibre Section IIV. http://texmin. nic.in/policy/Fibre_Policy_Sub_\%20Groups_Report_dir_mg_d_20100608_7.pdf

National Council of Applied Economic Research (2009).Assessing the Prospects for India's Textile and Clothing Sector.http://www.texmin.ic.in(24 Şubat 2013)

Canadian Textil Tecnologies Group. (2008). For The Canadian Textile Industry. http://www. ic.gc.ca/eic/site/trm-crt.nsf/vwapj/textile-textiles_eng.pdf (22 Şubat 2013)

Ramkumar, S. ve Singh, V. (2011). Technical Textiles Opportunities. Nonwovens and Advanced Materials Laboratory Texas Tech University. http://www.technotexindia.in/presentations/ RAM-KUMAR.pdf (03 Mart 2013)

Özdizdar, A.(2004). Teknik Tekstil Sektör Araștırması. İstanbul: İstanbul Ticaret Odası.

Özipek, B. (27.06.2007). Yeni Tekstiller. Dünyada ve Türkiye'de Akıllı Testiller. İstanbul: İstanbul Ticaret Odası.

Özsağır, A.(1999) Cumhuriyetin 75.Yılında Gaziantep Sanayisi . Küçükdağ, Y. (Ed).(1999). Cumburiyet'in 75. Yılına Armağan Gaziantep. Gaziantep Üniversitesi Kültür Vakfi Yayınları.

Akalın, M. (2005). Tekstilde Yeni Ufuklar Teknik Tekstil. Teknik Tekstiller: Tanımı, Kapsamı, Uygulama Alanları. İstanbul: İstanbul Ticaret Odası.

Arslan, K.(2009). Üretim ve Dış Ticaret. Teknik Tekstiller Genel ve Güncel Bilgiler. İstanbul: Müstakil Sanayici ve İşadamları Derneği

Kanık, M.(2011). Teknik Tekstil 2011Frankfurt Fuar Teknolojik Değerlendirme Raporu. Bursa Tekstil\&Konfeksiyon ve Ar-ge Merkezi.

Altun, Ş.(2011). Teknik Tekstil 2011Frankfurt Fuar Teknolojik Değerlendirme Raporu. Bursa Tekstil\&Konfeksiyon ve Ar-ge Merkezi.

İstanbul Tekstil Konfeksiyon İhracaţı Birlikleri. (2005). Teknik Tekstil Üzerine Genel ve Güncel Bilgiler. Mart 2005. İstanbul.

İstanbul Tekstil Konfeksiyon İhracatçı Birlikleri. (2008). Teknik Tekstil Üzerine Genel ve Güncel Bilgiler. Haziran 2008. İstanbul.

İstanbul Tekstil Konfeksiyon İhracaţı Birlikleri. (2011). Tekstil ve Konfeksiyon Sektörleri Açısından Almanya. Ekim 2011. İstanbul. 
İstanbul Ticaret Odası. (2006). Teknik Tekstil Endüstri Devrimine Aday [Electronic Version]. http://ns2.hiperkitap.com/ekitap/notsubscribed.jsp(15 Ekim 2012)

Haberler (14 Şubat 2012).SDÜ'nün Ses Emici Projesine Ödül. s.1. https://www.haberler.com/ sdu-nun-ses-emici-projesine-odul-3359017-haberi/

Aras, G.(2006).Avrupa Birliği ve Dünya Pazarlarına Uyum Açısından Türk Tekstil ve Konfeksiyon Sektörünün Rekabet Yeteneği Finansal Yaklaşım. Ocak 2006 İstanbul: Om Yayınevi

Vikipedi Özgür Ansiklopedi.(2012) Lif. http://tr.wikipedia.org/wiki/Lif (9 Aralık 2012)

Tekstil, Moda, Perakende, Tekstil Terimleri Sözlüğü.(2013). http://www.tekstilteknik.com/Referanslar/Tekniktekstiller.asp (6 Ocak 2013)

Kobi İşbirliği Kümelenme Projesi.(2013).http://www.smenetworking.gov.tr/detay.cfm?MID=28 (02 Temmuz 2013)

Uluslararası Ticareti Geliştirme Merkezi. (2012) Ticaret İstatistikleri http://www.trademap. org/Country_SelProduct.aspx (31 Aralık 2012)

Türkiye Odalar ve Borsalar Birliği. (2012) Sanayi veritabanı http://www.resmigazete.gov.tr/eskiler/2012/06/20120619-1.htm (25 Şubat 2013)

Türkiye Cumhuriyeti Resmi Gazetesi. (2012) 2012/3305 Sayılı Bakanlar Kurulu Kararı http:// sanayi.tobb.org.tr/kod_bulma_gtip.php(10 Kasım 2012)

Australian Trade Comission. (2011) Technical Textiles to Germany http://www.austrade.gov. au/Technical-textiles-to-Germany (30 Mart 2013)

The Québec Technical Textiles Industry Focused on the Future.(2013). http://collections.banq. qc.ca/ark:/52327/bs1944001 (13 Nisan 2013)

Facts and Figurese (2013). http://www.edana.org/discover-nonwovens(13 Nisan 2013)

Exporters Directory Shortened(2013). http://technotex.gov.in/Exporters\%20Directory\%20 Shortened\%20v1.0\%20260609.pdf (13 Nisan 2013)

Brazil is Growing Market for Technical Textiles \& Nonwovens Sector (2010). http://www. fibre2fashion.com/news/Association-news/acimit/newsdetails.aspx?news_id=81649 (15 Nisan 2013)

Trends and Cases in Textile Industrial Clusters (2006). http://archive.europe-innova.eu/index. jsp?type=page\&lg=en\&cid=7271 (15 Nisan 2013)

USA Commercial Service(2011). Japan: Industrial Fabrics Market. http://www.globaltrade. net/f/market-research/text/Japan/Textiles-Apparel-Leather-Footwear-Accessories-Industrial-Fabrics-Market.html

French Technical Textiles Industry: Evolving \& Competitive(2013). http://www.textileworld.com/Articles/2013/March/March_April_issue/NWTT_French_Technical_Textiles. html(17 Nisan 2013)

Functional and Technical Textiles in France(t.y.) http://static.canalblog.com/storagev1/textilestech.canalblog.com/docs/Functional_and_technical_textiles_in_France_.pdf(01.03.2013)

France's Textile and Clothing Industry(t.y.) http://portale.parma.it/fashion-net/allegato. asp?ID $=458190$

Federation of The Textile, Wood and Furniture Industries (2013) http://www.febeltex.be/content/default.asp?PageID=22\&languagecode=en (17 Nisan 2013)

Xe Currency Converter (2013). http://www.xe.com/currencyconverter/(22 Nisan 2013)

Nonwoven Industry(2008) India:Rising Opportunities in Nonwovens and Technical Textiles

http://www.nonwovens-industry.com/issues/2008-02/view_features/india8200rising-opportunities-in-nonwovens-an/( 24 Nisan 2013)

International Textile Machinery Exhibition(2012).Dünya Teknik ve Istanbul Toplantısı,Tekstil: Hightex 2012.http://www.itm2012.com/itmeng/news6.html (28 Nisan 2013)

European Disposables and Nonwovens Association (2013). What are Nonwovens http://www. edana.org/discover-nonwovens/what-are-nonwovens- (05 May1s 2013)

Associaiton of the Nonwovens Fabrics Industry (2013). About Nonwovens http://www.inda. org/about-nonwovens/ (05 Mayis 2013) 